\title{
Cereal Mycotoxins Contamination and Associated Risk Factors: A Consideration of Lringa Municipality in Tanzania.
}

Rahma Rajabu ( $\sim$ allyrahma96@gmail.com)

Ruaha Catholic University

Peter Chilipweli

Ruaha Catholic University

Revocatus Mang'ara

Ruaha Catholic University

\section{Research Article}

Keywords: Mycotoxin, Aflatoxin Risk factors, contamination, cereals. Pallet

Posted Date: February 8th, 2021

DOl: https://doi.org/10.21203/rs.3.rs-152394/v1

License: (1) This work is licensed under a Creative Commons Attribution 4.0 International License.

Read Full License 
TITLE: Cereal Mycotoxins Contamination and associated risk factors: A consideration of Iringa Municipality in Tanzania.

Authors: Rahma Ally Rajabu ${ }^{1}$, Peter M chilipweli ${ }^{2}$, Revocatus Mang’ara ${ }^{3}$.

Email Address: allyrahma96@gmail.com,chilipwelipeter64@ gmail.com, revomangara@gmail.com.

\section{Affiliation:}

1. Rahma Ally Rajabu, Corresponding author.

Department of environmental health sciences, Ruaha catholic university (RUCU)P.O.BOX 774 Iringa, Tanzania. Email: allyrahma96@gmail.com.

\section{Peter Martin Chilipweli}

Department of environmental health sciences, Ruaha catholic university (RUCU)P.O.BOX 774 Iringa, Tanzania. Email: chilipwelipeter64@gmail.com

\section{Revocatus Mang'ara}

Department of environmental health sciences, Ruaha catholic university (RUCU)P.O.BOX 774 Iringa, Tanzania. Email: revomangara@gmail.com 


\section{ABSTRACT}

Background: Mycotoxins have various serious health effects when consumed by humans and animals including, acute aflatoxicosis when consumed in high levels. Chronic exposure to low levels of contamination in crops increases liver cancer risk and can suppress the immune system, particularly for populations that test positive for the hepatitis B virus (HBV). Also when contaminated foods are consumed by young children can lead to stunting and growth impairment.

Methods: A cross-sectional study design was carried out at one-time point .A total of 296 participants were enrolled. Surveys were conducted to determine risk factors for mycotoxin contamination in cereal in Iringa municipality. The study involved 4 wards namely Kwakilosa, Mlandege, Kihesa and Ruaha, in which 2 streets were selected from each ward where a minimum of 25 respondents were selected in each street by using quota and convenience sampling techniques. A questionnaire was administered to assess community's level of knowledge on mycotoxin contamination in cereals. A checklist was used to explore the conditions and facilities used store cereal,

Results: Majority of respondents 71(36.2\%) their age ranged 29-39 years, few being above 61 making up $3.6 \%$. Also $87.2 \%$ did not have knowledge on mycotoxin contamination in cereals, while only $12.8 \%$ had knowledge on mycotoxin contamination in cereals which showed that $56.6 \%$ of the storage rooms were not properly ventilated, with proper ventilation were $43.4 \%$ of the total storage rooms. The study also revealed that majority $67.1 \%$ placed cereals in rooms with no ceilings, while also $60.8 \%$ leaned their cereal bags directly against the wall without leaving space contributing to favorable conditions for fungal growth as it increases the likelihood of cereal bags to absorb moisture from the wall, $86.7 \%$ cleaned their packaging material before use while only $46.9 \%$ and $44.8 \%$ cleaned their rooms and milling machines before storage or processing respectively. Majority $80.4 \%$ used woven sacks while $22.4 \%$ and $46.9 \%$ had pallets and tarpaulin respectively.

Conclusion: Majority of respondents 171 individuals equivalent to $87.2 \%$ did not have knowledge on mycotoxin contamination in cereals, while only 25 individuals equivalent to $12.8 \%$ had knowledge on mycotoxin contamination in cereals. While the storage conditions and facilities used, showed that majority of individuals 111(77.6\%) piled up bags of cereals on bare floors (no pallets) and 87(60.8\%) leaned them directly against the walls with majority of them $96(67.1 \%)$ placed under roofs with no ceiling.

Keywords: Mycotoxin, Aflatoxin Risk factors, contamination, cereals. Pallet. 


\section{Background}

Mycotoxins are naturally occurring toxic secondary metabolites produced by filamentous fungi mainly Aspergillus flavus and Aspergillus parasiticus which can contaminate many kinds of agricultural products. Toxigenic fungi are capable of growing under a wide range of atmospheric conditions depending on the species and they can contaminate crops during pre-harvest, immediate post-harvest, storage, transport and processing (Bennett \& Klich, 2003).

Aflatoxins and fumonisins are among the main types of mycotoxins of significant public health concern due to their widespread contamination in foodstuffs as well as chronic and acute health effects in human (IARC,2002; Bakirdere et al., 2012; Felicia Wu, et al 2014). There are several types of aflatoxins which include aflatoxin B1 (AFB1), aflatoxin B2 (AFB2), aflatoxin G1 (AFG1) and aflatoxin G2 (AFG2) which are produced by these fungi. The B1 form is recognized as one of the most toxic and carcinogenic substances found in nature (TFDA,2012).

The most fatal human aflatoxicosis outbreak occurred in Kenya, 2004, with 317 recorded cases of acute hepatitis and 125 deaths (Claudia Probst, et al., 2004). Food poisoning linked to 54 cases and 14 recorded deaths in two regions namely Dodoma and Manyara, Tanzania. Another 115 samples from maize flour were tested by TFDA, out of which 52 samples equivalent to 45 percent proved to have high rates of aflatoxins (The Guardian, 2016). A total of eight cases of suspected aflatoxicosis, including four deaths (case fatality rate 50 percent) in Dodoma and Manyara, displayed symptoms of abdominal distention and pain, jaundice, vomiting and altered mental status (WHO, 2017).

A studied conducted in Iringa, Kilimanjaro and Tabora showed highest concentration of AFB1 in Kilimanjaro while Iringa and tabora had more samples with Aflatoxin detactable where their concentration were higher during storage, DON were particularly higher in Iringa Region (Geary, PA, Chen, G, Kimanya, ME et al., 2016). 


\section{MYCOTOXIN CONTAMINATION IN CEREALS AND THEIR ASSOCIATED EFFECTS}

\section{Aflatoxin}

Aflatoxins occur in nuts, cereals and rice under conditions of high humidity and temperature and present a risk to human health that is insufficiently recognized. Aflatoxins include both $B$ and $G$ aflatoxins. Aflatoxins M1 and M2 are oxidative metabolic products of aflatoxins B1 and B2 produced by animals following ingestion, and so appear in milk (both animal and human), urine and faeces. Aflatoxins are acutely toxic, immunosuppressive, mutagenic, teratogenic and carcinogenic compounds. The main target organ for toxicity and carcinogenicity is the liver [WHO, 1999].

Following the evaluation of epidemiological and laboratory results carried out in 1987 by the International Agency for Research on Cancer (IARC) naturally occurring mixtures of aflatoxins, were classified as Group 1 carcinogens, except for aflatoxin M1, which is possibly carcinogenic to humans. Aflatoxins have been suggested as an etiological factor in encephalopathy and fatty degeneration of viscera, similar to Reye syndrome, which is common in countries with a hot and humid climate. The clinical picture includes enlarged, pale, fatty liver and kidneys and severe cerebral oedema, accompanied by headache, nausea and jaundice (WHO, 1999).

\section{Ochratoxins}

Ochratoxinsare secondary metabolites of Aspergillus and Penicillium strains, found on cereals (dry beans, maize, wheat, oats), coffee and bread, as well as on all kinds of food commodities of animal origin in many countries. The most frequent is ochratoxin A (OTA), which is also the most toxic. It has been shown to be nephrotoxic, immunosuppressive, carcinogenic and teratogenic in all experimental animals tested so far. This mycotoxin has been proposed as the causative agent of endemic nephropathy, the main features of endemic nephropathy are bilateral, primarily chronic lesions of the renal cortex (tubular degeneration, interstitial fibrosis and hyalinization of the glomeruli). In the advanced stage of the disease, the size and weight of kidneys are remarkably reduced, with diffuse cortical fibrosis, usually without signs of inflammation (WHO, 1999).

\section{Fumonisins}

Fumonisins are mycotoxins produced throughout the world by Fusarium moniliforme and related species when they grow in maize. Fumonisins B1 and B2 are of toxicological significance, while the others (B3, B4, A1 and A2) occur in very low concentrations and are less toxic (WHO, 1999). They are found predominantly in maize and in a maize based animal feeds, $\mathrm{FB}(1)$ is a neurotoxic, hepatotoxic and nephrotoxic in animals, and it has been classified as possible carcinogen to humans. The cellular mechanisms behind FB (1) induced toxicity include the induction of oxidative stress, apoptosis and cytotoxicity as well as alterations in cytokine expression (Stockman \& Savolainen, 2008). 


\section{Zearalenone}

Zearalenone (previously known as F-2) is produced mainly by Fusarium graminearum and related species, principally in wheat and maize but also in sorghum, barley and compounded feeds (WHO, 1999). ZEN affects hematological and immunological parameters in humans and rodents. The compound can cause cell death, lipid peroxidation, inhibit protein and exert genotoxic effects. ZEN may cause increased phagolysosomal in the kidney, can induce liver carcinoma, pituitary adenoma and renal toxicity (Gao F, Jiang LP, et al., 2013).

\section{Deoxynivalenol (DON)}

DON is the most frequent myotoxin found in corn, barley, sunflower seeds, rye and wheat, exposure to elevated levels DON causes nausea, vomiting and diarrhea in farm animals and lower doses in cattle have been linked to weight loss and food refusal. Prolonged exposure to DON can cause reduced growth and damage organs such as spleen, thymus, liver and heart. Also known to be powerful inhibitors of protein synthesis by reacting with components of ribosomes (Lubinda Mbundi, et al., 2014).

\section{Patulin}

Patulin is produced by variety of molds especially Aspergillus and Penicillium species, which are commonly detected in variety of food stuffs such as cEreals, vegetables and fruits such as apples and pears. Patulin is generally a potent toxin but due to its demonstration of genotoxicity it shows potential signs of being carcinogen. WHO recommended maximum levels of patulin are $50 \mathrm{ng} / \mathrm{mL}$ in apple juice and cider, $25 \mathrm{ng} / \mathrm{g}$ in solid apple products and 10ng/g in products for infants and young children in the European Union, In addition the Joint FAO/WHO Expert Committee on Food Additives (JECFA) has established provisional maximum allowable daily intake of $0.4 \mu \mathrm{g} / \mathrm{g}$ of body weight per day for patulin (Lubinda Mbundi, et al., 2014).

\section{Egort alkaloids}

Ergot is the common name of the sclerotia of fungal species within the genus Claviceps, which produce ergot alkaloids. Ergot alkaloids are also secondary metabolites of some strains of Penicillium, Aspergillus and Rhizopus spp. The source of the ergot strongly influences the type of alkaloids present, as well as the clinical picture of ergotism. Claviceps purpurea produces ergotamine and ergocristine alkaloids, which cause the gangrenous form o fergotism because of their vasoconstrictive activity. The initial symptoms are oedema of the legs, with severe pains. Paraesthesias are followed by gangrene at the tendons, with painless demarcation (WHO, 1999). Ergotism is extremely rare today, primarily because the normal grain cleaning and milling 


\section{CEREAL STORAGE}

Toxigenic fungi are associated with both pre-harvest and postharvest mycotoxin contamination in cereals, The severity of post-harvest fungal infection and propagation during prolonged periods of grain storage can be managed more predictably through GAP and good manufacturing practices (GMP) that ensure that moisture levels in stored grain remain below levels. However, research has confirmed that spores of such species are ubiquitous in soils, equipment, and storage structures despite diligent cleaning. Therefore, it is important for the storage room to be designed properly such that it facilitates sanitary conditions to prevent mold growth, also storage equipments used should be well designed and frequently cleaned preventing mycotoxin contamination [Codex Alimentarius Commission (CAC), 2003]

The store interior Walls are to be kept clean, free of cracks and white washed, floors should be free from cracks if any,should be filled with concrete and fill all floor joints with sand/ bitumen/cement mix to prevent food collecting that can attract insects and damage the cereals/grains making them susceptible to mycotoxin contamination [World Food Programme (WFP), 2012].

Bins, silos, sheds and other buildings intended for grain storage are dry, well-vented structures that provide protection from rain, snow, ground water, moisture condensation, and the entry of rodents, birds and insects that cannot only contaminate grain, but damage grain kernels to render them more susceptible to mould infection. storage structures should be designed so as to minimize wide fluctuations in the temperature of the stored grain (CAC, 2003). Areas surrounding stores are well maintained. In particular, lawns, areas not covered with concrete and intake pits. Sites to be free-draining. Rodent traps are positioned in the areas surrounding food and feed materials and waste storage locations. Fencing is important for securing unauthorized entry, there should be enough lighting, gates and doors are fitted with good quality padlocks (WFP, 2012).

\section{STORAGE FACILITIES}

Open weave sacks

For keeping grain on farm for periods of three months or less, open weave sacks are the most convenient option. Sacks may be made of polypropylene, jute or sisal. If second-hand bags are to be used then they must be thoroughly cleaned before before filling with grain. The bags should not be overfilled with grain, after filling they should be closed by hand stitching or by using a stitching machine (WFP, 2012).

Metal silos

Metal silos are insect-proof but can be made hermetic by tying rubber from a bicycle inner tube very tightly around the grain input and output ports. In order to have a quick change in gas 
composition, a lighted candle may be placed on the grain surface at the time the inlet and outlet ports are sealed (do not do this with plastic grain stores as they may catch fire).

The candle will burn the oxygen and in so doing create carbon dioxide, this will extinguish the candle and within two weeks will kill any insects that are present. Do not open the silos until after two weeks as this will let in fresh air and the insects will survive (WFP, 2012).

\section{Pallets}

The sacks must be prevented from making contact with the floor or walls of the house, from which they might absorb moisture, causing the grain to rot. To do this the bags are placed on pallets made of sticks and/or stones so they are suspended at least $12 \mathrm{~cm}$ above the floor (if no pallets can be constructed then a plastic sheet could be used) and away from contact with the wall (WFP, 2012).

\section{Tarpaulins}

Tarpaulins that can be used to cover bag stacks to prevent insect infestation moving from one stack to another and as a base on which to do grain conditioning operations. Also can be used to cover bag stacks when store is cleaned to prevent dust that may contain fungal spores to contaminate cereals (WFP, 2012)..

\section{SANITATION OF THE STORE ROOM AND ITS FACILITIES}

Before the new harvest arrives in store it is best to ensure that all the old harvest has been discharged. If it cannot be discharged then it would be helpful to isolate it from the new harvest by covering with a tarpaulin and weighting the edges of the tarpaulin with lengths of wood or stones. This will help reduce the movement of insects from old infested grain to the new grain (WFP, 2012).

The store should then be thoroughly swept, to remove all grain residues from the floor, any cracks and crevices, or sliding door runners. The grain residues should be taken out of the store and burnt or fed to animals. The floor should be thoroughly inspected for cracks and if any are found they should be filled with cement. Cracks in walls should also be filled (WFP, 2012).

Once the store is clean the pallets should be laid out to receive the incoming crop, with a gap of $1 \mathrm{~m}$ from the store walls. The pallets should be brushed clean to remove any old grain or grain dust. They should be checked for any protruding nails, which might tear grain sacks, any nails should be removed or hammered in (WFP, 2012).

Storage facilities should be cleaned prior to receiving grain to remove dust, fungal spores, grain, crop residues, animal and insect excreta, soil, insects, foreign material such as stones, metal and broken glass, and other source of contamination (CAC, 2003). 


\section{FOOD PROCESSING METHODS THAT REDUCE RISK OF FUNGI CONTAMINATION IN CEREAL.}

Food processing can further reduce mycotoxin levels by physical removal and decontamination by chemical or enzymatic transformation of mycotoxins into less toxic products (Petr Karlovsky, et al., 2016).

\section{Sorting}

Unprocessed cereals in bulk trading often contain dust and admixtures, broken and damaged kernels usually contain most of mycotoxin contamination, though they constitute only 3-6\% of the bulk load (Petr Karlovsky, et al., 2016).

Hand sorting of visibly damaged kernels is an effective method of reducing exposure to mycotoxins such as DON and fumonisins (Felix D'Mello, 2003). Experimental research conducted in south Africa showed that hand sorting and washing procedures reduced fumonisins contamination in maize and porridge by $84 \%$ and $65 \%$ respectively (Mycotoxins: Advances in Research and Application, 2011)

\section{Sieving cleaning}

Removing kernels with extensive mold growth, broken kernels, and fine materials such as dirt and debris can be achieved by sieve cleaning, which significantly lowers total mycotoxin contamination. After sieving off corn screenings, it was determined that intact kernels contained about 10 times less fumonisins than broken corn kernels or smaller parts. Removing broken kernels and smaller parts from maize reduced DON and ZEN contamination by around 70-80\% however, up to $69 \%$ of the total maize was rejected as well (Petr Karlovsky, et al., 2016).

\section{Flotation and density segregation}

The different physical properties of mold-damaged kernels compared to non-damaged kernels can be exploited to separate them by density segregation or by fractionation on gravity tables. Ergot containing ergot alkaloids can be efficiently separated from rye grains by flotation in $\mathrm{NaCl}$ solution. Removal of corn buoyant in water reduced aflatoxin levels by $60 \%$, at a mass loss of 22\% (Petr Karlovsky, et al., 2016).

\section{Washing}

Water-soluble mycotoxins can be partly washed from the surface of grains. ZEN is barely water soluble, but well solublein alkaline solutions. Therefore, sodium carbonate solutions are often used as an alternative to improve the effectiveness of washing steps. Washing barley and corn three times in distilled water reduced the DON content by $65-69 \%$, while ZEN concentrations were reduced by $2-61 \%$. Using $1 \mathrm{~mol} / 1$ sodium carbonate solution for the first wash step reduced DON by $72-75 \%$ and ZEN by $80-87 \%$ (Petr Karlovsky, et al., 2016). 


\section{Dehulling}

The outer layers of grain are removed by dehulling techniques, which are formerly composed of an indispensable processing step prior to grinding. Limitation of fungal colonization and mycotoxin accumulation to surface layers of the kernel are prerequisites for the success of dehulling in mycotoxin content reduction. This condition is fulfilled for aflatoxins in maize, dehulling of maize can therefore remove up to $93 \%$ of aflatoxins (Petr Karlovsky, et al., 2016).

\section{Heat treatment}

The time/temperature combination undoubtedly remains one of the most important interventions by which industrial processing can affect the mycotoxin content in a finished food product. Aflatoxins can be reduced by extrusion by $50-80 \%$, depending on grain moisture and temperature. Roasting can reduce the levels of aflatoxins by $50-70 \%$ in peanuts and pecans and by $40-80 \%$ in maize. Pure aflatoxin B1 (AFB1) was destroyed by temperatures above $160^{\circ} \mathrm{C}$, soy bean matrix accelerated the process. Roasting can reduce the content of OTA in coffee beans by up to $97 \%$, depending on the temperature and particle size (Petr Karlovsky, et al., 2016). 


\section{METHODS:}

\section{Study Area}

The study was conducted in Iringa municipal which is one among the five districts of Iringa Region. The municipal extends between latitude $7^{\circ} 45^{\prime}$ and $7^{\circ} 50^{\prime}$ South of equator and longitude $35^{\circ} 40^{\prime}$ and $35^{\circ} 45^{\prime}$ East. Iringa municipal has an area of 176 square kilometers with 18 wards namely Kihesa, Mkwawa, Mwangata, Kitwiru, Ruaha, Mtwivila, Ilala, Makorongoni, Mivinjeni, Kitanzini, Mshindo, Gangilonga, Isakalilo, Nduli, Kwakilosa, Igumbilo, Mkimbizi and Mlandege. The estimated total population of Iringa Municipal is 151,345 people, where 71,932 are males and 79,413 females. Iringa urban economy is dependent on agriculture and livestock, industry and commerce, almost $40 \%$ of the population of the municipality depends on agriculture and livestock in the fringes of Iringa municipality. About 72,000 hectares out of 162,000 within the municipality are suitable for both agriculture and livestock activities the crops cultivated are maize, beans, potatoes, sorghum, paddy, wheat, sunflower, tea, tomatoes and vegetables. Figure 1 below.

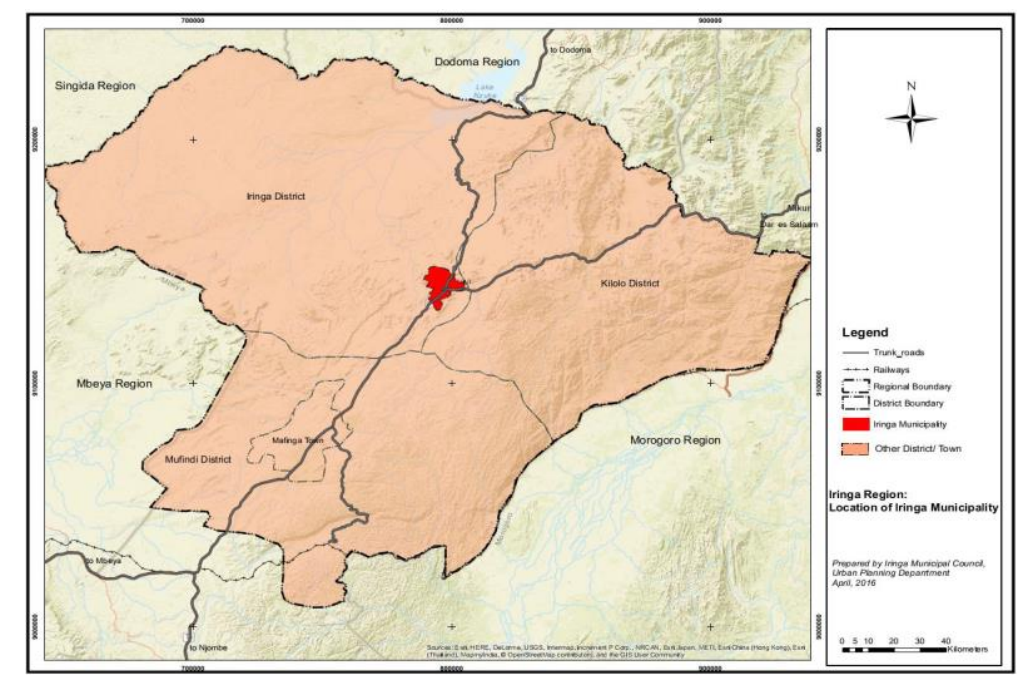

Figure 1: Iringa Municipality map (Source Google Map).

\section{Study design and setting.}

A cross-sectional study design was carried out at one-time point ohe study was descriptive in form of survey. Usually there is no hypothesis as such, but the aim is to describe a population or subgroup within the population with respect to an outcome and set of risk factors, the purpose of the study was to find prevalence of the outcome of interest, for the population or subgroups within the population at a given time point (Kate Ann Levin, 2006).

A quantitative research approach was used, which emphasized objective measurements and the statistical, mathematical or numerical analysis of data collected through questionnaires and checklist. The approach focused on gathering numerical data and generalizing it across groups of people or to explain a particular phenomenon (Babbie, Earl R., 2010). 


\section{Sampling.}

Multistage sampling method was used to select participants. Sample frame of 18 wards was used to select 4 wards randomly. From each ward that was selected a sampling frame consisting of all streets was used to select 2 streets from each selected ward, in which a total of 8 streets was obtained.

From the 8 streets selected, a minimum of 25 respondents was obtained from each street by using both quota and convenience sampling techniques. Quota sampling technique was used to select respondents of a sample characteristic (age), in which the study focused on respondents who are 18 years and above while convenience sampling technique was used to obtain readily available respondents, who were found buying, processing (milling and grinding) or selling cereals at that period of time, until a total of 196 respondents was reached.

\section{Data collection.}

Objectives were met using two questionnaires and a checklist administered in Iringa Municipality particularly in 4 wards namely Kwakilosa, Mlandege, Kihesa and Ruaha. The first questionnaire assessed general knowledge that respondents have on mycotoxin contamination in cereals and the second questionnaire was used to assess respondents' awareness on food processing methods used to reduce mycotoxin contamination in cereals.

Lastly, a checklist explored storage facilities and conditions used to store cereals, in which the researcher was able to determine if storage conditions used favor mold growth facilitating mycotoxin contamination in cereals.

\section{Data analysis}

Data collected from respondents were analysed using Statistical Packages for Social Sciences (SPSS) version 22.0 for quantitative data, which were then presented in graphs, charts and tables. 


\section{RESULTS.}

\section{Social-demographic characteristics of respondents.}

Table 1 shows that majority of respondents $(76.5 \%)$ were males while $(23.5 \%)$ being female. Iringa one among the region that engage highly in agricultural activities, the occupation distribution showed Majority (29.6\%) were owners of cereal processing stations and cereal retailers $(25 \%)$ with the least $(16.3 \%)$ and $(10.7 \%)$ being entrepreneur and unemployed.

Table 1: Demographic Data of Respondents

\begin{tabular}{|c|c|c|c|}
\hline Characteristics & & Number & Percentage \\
\hline \multirow[t]{2}{*}{ Gender } & Male & 150 & 76.5 \\
\hline & Female & 46 & 23.5 \\
\hline \multirow[t]{5}{*}{ Age } & $18-28$ & 56 & 28.6 \\
\hline & $29-39$ & 71 & 36.2 \\
\hline & $40-50$ & 42 & 21.4 \\
\hline & $51-61$ & 20 & 10.2 \\
\hline & Above 61 & 7 & 3.6 \\
\hline \multirow[t]{4}{*}{ Education Level } & Primary & 76 & 38.8 \\
\hline & Secondary & 92 & 46.9 \\
\hline & Tertiary & 11 & 5.6 \\
\hline & No Education & 17 & 8.7 \\
\hline \multirow[t]{5}{*}{ Occupation } & Peasant & 36 & 18.4 \\
\hline & Cereal processor & 58 & 29.6 \\
\hline & Cereal retailer & 49 & 25.0 \\
\hline & Entrepreneur & 32 & 16.3 \\
\hline & Unemployed & 21 & 10.7 \\
\hline Total & & 196 & 100.0 \\
\hline
\end{tabular}

\section{KNOWLEDGE ON MYCOTOXIN CONTAMINATION IN CEREALS}

The study conducted showed that majority of the respondents that is 171 individuals equivalent to $87.2 \%$ did not have knowledge on mycotoxin contamination in cereals, while only 25 individuals equivalent to $12.8 \%$ had knowledge on mycotoxin contamination in cereals, Majority 11 (44\%) with knowledge on mycotoxin contamination in cereal were cereal processors. These findings 
corroborate those of other studies which reflected high level of ignorance concerning mycotoxin contamination and the fungi that produce them (Selestin Ngoma, Martin Kimanya, et. al., 2017).

The study (with respect to Table 2) showed that level of education had negative correlation with mycotoxin knowledge where by $(\mathrm{r}=-0.161, \mathrm{p}<0.05)$.

Table 2. Correlation between Mycotoxin knowledge and Education level

\begin{tabular}{|l|l|c|c|}
\hline \multicolumn{2}{|c|}{} & Mycotoxin Knowledge & Education Level \\
\hline Kendall's tau_b & Mycotoxin Knowledge & 1.000 & $-0.161^{*}$ \\
\cline { 2 - 4 } & Education Level & $-0.161^{*}$ & 1.000 \\
\hline Total & 196 & 196 \\
\hline
\end{tabular}

.Correlation is significant at the 0.05 level (2-tailed).

Table 3. Knowledge on factors for mycotoxin contamination in cereals

\begin{tabular}{|l|c|c|}
\hline Factors for mycotoxin contamination in cereal & Number & Percent \\
Poor storage conditions & 8 & 32.0 \\
\hline High moisture content & 3 & 12.0 \\
\hline Temperature & 1 & 4.0 \\
\hline Do not know & 13 & 52.0 \\
\hline Total & $\mathbf{2 5}$ & $\mathbf{1 0 0 . 0}$ \\
\hline
\end{tabular}

As in Table 3, 13 (52\%) Respondents out of 25(100\%) who had knowledge on mycotoxin contamination, did not understand corresponding factors causing the contamination.

Figure 2: Knowledge on acute health effects on consumption of mycotoxin contaminated cereal

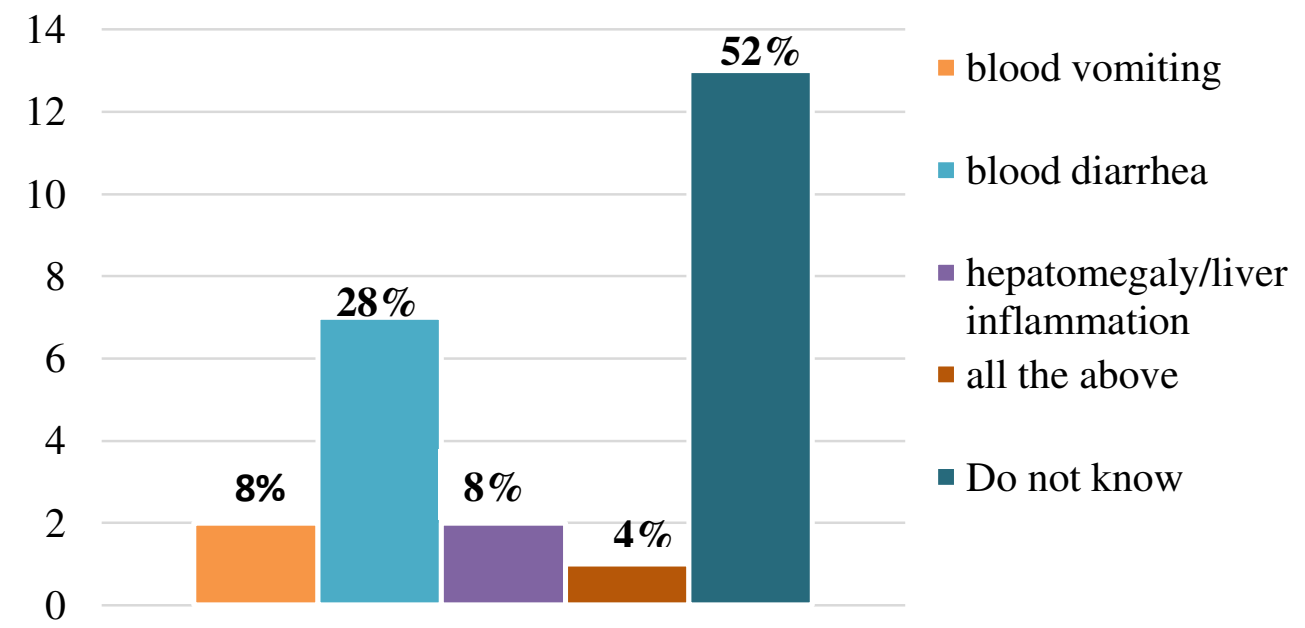

Majority 13 (52\%) of the total respondents with mycotoxin knowledge i.e. 25(100\%) in figure 2 understood that blood vomiting is the acute health effects associated with consumption of 
mycotoxin contaminated cereals while the few respondents $4 \%$ had also the knowledge of other corresponding acute health effects such as blood diarrhea and Liver inflammation.

\section{Figure 3: Knowledge on chronic health effects on consumption of mycotoxin contaminated cereal}

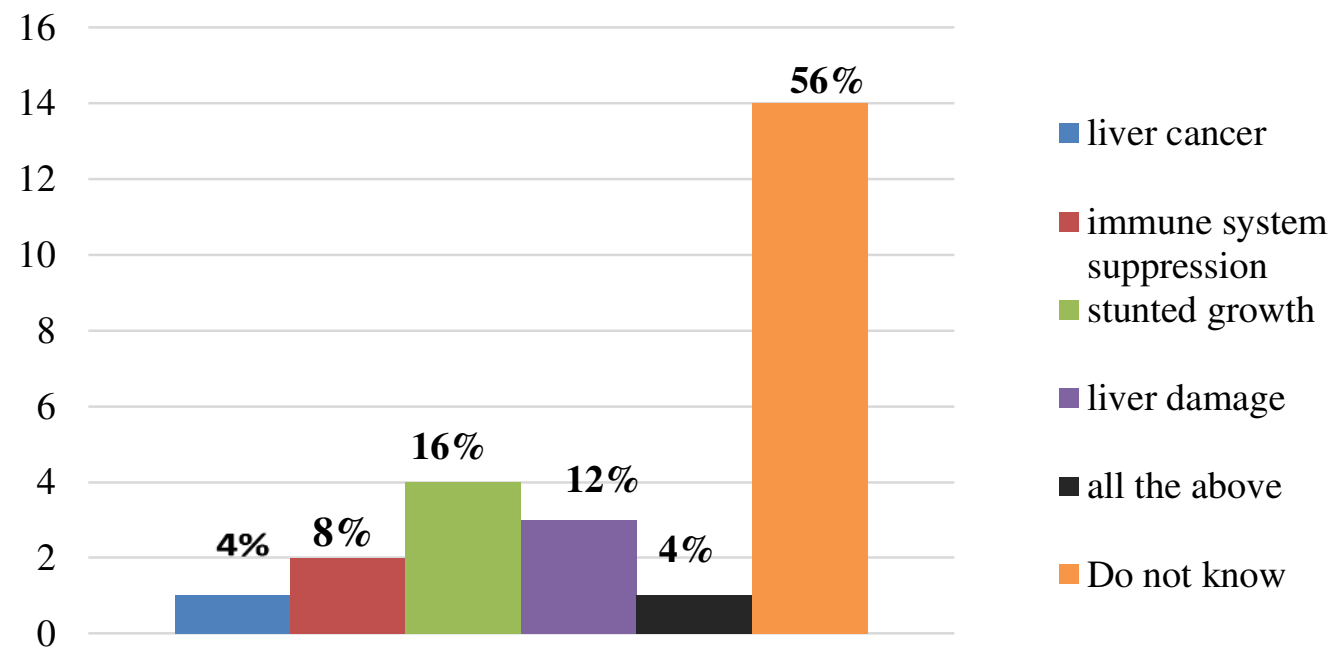

Majority 14 (56\%) of the total respondents with mycotoxin knowledge 25(100\%) in figure 3 were clueless on the chronic health effects associated with long term consumption of mycotoxin contaminated cereals. In Tanzania, according to the new, 2018 UNICEF-WHO classification, the level of stunting was considered "very high" $(\geq 30 \%)$ in 15 regions out of 26 , where among the most affected regions with a prevalence of stunting exceeding 40\% was Iringa Region with prevalence of $47.1 \%$ (Tanzania National Nutrition Survey using SMART Methodology (TNNS), 2018) Despite that few respondents $16 \%$ understood stunted growth can be one among the associated chronic health effect following long term intake of mycotoxin contaminated cereal. The least $4 \%$ of the had knowledge on the associated chronic health effects.

Generally, the result obtained corresponds to other studies which showed that a significant number of people in both developed and developing nations are not well informed on contaminants in foods (Ifeoluwa Adekoya, Patrick Njobeh, et. al, 2017). 


\section{CONDITIONS AND FACILITIES USED TO STORE CEREALS}

Majority of respondents $\mathbf{1 4 3}(\mathbf{7 3 \%})$ ) had an area to store cereal while few of them $\mathbf{5 3}(\mathbf{2 7 \%})$ did not have a storage room.

Table 4: Conditions present during cereal storage

\begin{tabular}{|c|c|c|c|}
\hline \multicolumn{2}{|c|}{ Criteria for storage conditions } & Number & Percent \\
\hline \multirow[t]{3}{*}{ Ventilation } & Proper Ventilation & 62 & 43.4 \\
\hline & No proper Ventilation & 81 & 56.6 \\
\hline & Total & 143 & 100.0 \\
\hline \multirow[t]{3}{*}{ Ceiling } & Have Ceiling & 27 & 32.9 \\
\hline & No Ceiling & 96 & 67.1 \\
\hline & Total & 143 & 100.0 \\
\hline \multirow{3}{*}{$\begin{array}{l}\text { Cereal bags placed } 6 \\
\text { to } 8 \text { inches away from } \\
\text { the walls }\end{array}$} & Yes & 56 & 39.2 \\
\hline & No & 87 & 60.8 \\
\hline & Total & 143 & 100.0 \\
\hline
\end{tabular}

Table 4 notes that majority $81 \%$ stored their cereals in rooms with improper ventilation while $67.1 \%$ stored in rooms with no ceiling where $60.8 \%$ did not place their cereal bags away from the walls.

Table 5: Sanitation conditions of cereal storage room

\begin{tabular}{|l|l|l|l|}
\hline Criteria for storage conditions & Number & Percent \\
\hline Room cleaned before storage & Yes & 67 & 46.9 \\
\cline { 2 - 4 } & No & 76 & 53.1 \\
\cline { 2 - 4 } & Total & 143 & 100.0 \\
\hline $\begin{array}{l}\text { Packaging materials cleaned } \\
\text { before storage }\end{array}$ & Yes & 124 & 86.7 \\
\cline { 2 - 4 } & No & 19 & 13.3 \\
\cline { 2 - 4 } & Total & 143 & 100.0 \\
\hline $\begin{array}{l}\text { Milling machines cleaned } \\
\text { before processing }\end{array}$ & Yes & 26 & 44.8 \\
\cline { 2 - 4 } & No & 32 & 55.2 \\
\cline { 2 - 4 } & Total & 143 & 100.0 \\
\hline
\end{tabular}

The sanitation condition of cereal storage rooms as indicated in table 5 shows that Majority $53.1 \%$ do not clean their rooms before storage but $86.7 \%$ clean their packaging materials before storing cereals in them while milling machines for those processing cereals majority are not cleaned prior to processing. 
Table 6: Facilities used during cereal storage

\begin{tabular}{|c|c|c|c|}
\hline \multicolumn{2}{|c|}{ Storage facilities } & Numbers & Percent \\
\hline \multirow{4}{*}{$\begin{array}{l}\text { Storage packaging } \\
\text { materials }\end{array}$} & Polyethylene bag & 13 & 9.1 \\
\cline { 2 - 4 } & Containers & 15 & 10.5 \\
\cline { 2 - 4 } & Woven sacks & 115 & 80.4 \\
\cline { 2 - 4 } & Total & 143 & 100 \\
\hline \multirow{4}{*}{ Pallets } & Present & 32 & 22.4 \\
\cline { 2 - 4 } & Not present & 111 & 77.6 \\
\cline { 2 - 4 } & Total & 143 & 100 \\
\hline \multirow{3}{*}{ Tarpaulin } & Present & 67 & 46.9 \\
\cline { 2 - 4 } & Not present & 76 & 53.1 \\
\cline { 2 - 4 } & Total & 143 & 100 \\
\hline
\end{tabular}

Table 6 that most of respondents $80.4 \%$ used woven sacks packaging material for storing cereals while $77.6 \%$ had no pallets with only $46.9 \%$ having Tarpaulin that can be used for placing cereal for sun drying purpose.

\section{FOOD PROCCESSING METHODS USED TO REDUCE RISK OF FUNGI CONTAMINATION IN CEREALS.}

Table 7: Respondents who sort damaged cereals before further Processing

\begin{tabular}{|l|c|c|}
\hline \multicolumn{1}{|c|}{ Sorting of damaged cereals } & Number & Percent \\
\hline Sort and discard damaged cereal & 49 & 25.0 \\
\hline Sort and damaged cereals use as feed & 48 & 24.5 \\
\hline Do not sort & 99 & 50.5 \\
\hline Total & 196 & 100 \\
\hline
\end{tabular}

Sorting of damaged cereals is one among food processing methods that can be used to reduce the risk of fungi contamination in cereals, Table 7 indicayes Majority 50.5\% do not sort cereals while among $49.5 \%$ who sort $24.5 \%$ uses the damaged cereals as feed. 
Table 8: Awareness on sorting and heat method reduce the risk of fungi contamination in cereal

\begin{tabular}{|l|l|c|c|}
\hline \multicolumn{2}{|l|}{ Reduction in risk of fungi contamination } & Number & Percent \\
\hline \multirow{2}{*}{$\begin{array}{l}\text { sorting of spoiled/damaged } \\
\text { cereals reduces the risk of } \\
\text { fungi contamination }\end{array}$} & Yes & 84 & 42.9 \\
\cline { 2 - 4 } & No & 112 & 57.1 \\
\cline { 2 - 4 } & Total & $\mathbf{1 9 6}$ & $\mathbf{1 0 0}$ \\
\hline \multirow{4}{*}{$\begin{array}{l}\text { Heat method used to } \\
\text { reduce mycotoxin } \\
\text { contamination in cereal }\end{array}$} & Roasting & 12 & 6.1 \\
\cline { 2 - 4 } & Frying & 14 & 7.1 \\
\cline { 2 - 4 } & Smoking & 53 & 27.1 \\
\cline { 2 - 4 } & Sub Total & 79 & 40.3 \\
\cline { 2 - 4 } & Do not Know & 117 & 59.7 \\
\cline { 2 - 4 } & Total & $\mathbf{1 9 6}$ & $\mathbf{1 0 0}$ \\
\hline
\end{tabular}

Majority of respondents 57.1 and 59.7 respectively as shown in table 8 are not aware that sorting of spoiled/damaged cereals and heat method reduces the risk of mycotoxin contamination in cereals.

\section{Table 9: Drying Method}

\begin{tabular}{|l|l|c|c|}
\hline \multicolumn{2}{|l|}{ Drying Method } & Number & Percent \\
\hline \multirow{2}{*}{$\begin{array}{l}\text { Dry cereals before further } \\
\text { processing/storage }\end{array}$} & Yes & 109 & 55.6 \\
\cline { 2 - 4 } & No & 112 & 44.4 \\
\cline { 2 - 4 } & Total & $\mathbf{1 9 6}$ & $\mathbf{1 0 0}$ \\
\hline \multirow{2}{*}{$\begin{array}{l}\text { Drying reduces risk of fungi } \\
\text { contamination in cereal }\end{array}$} & Yes & 80 & 40.8 \\
\cline { 2 - 4 } & No & 116 & 59.2 \\
\cline { 2 - 4 } & Total & $\mathbf{1 9 6}$ & 100 \\
\hline
\end{tabular}

Despite Majority 55.6\% dry their cereals before further processing/storage, majority $59.2 \%$ as indicated in table 9 did not understand that the method reduces the risk of fungi contamination in cereal

\section{CONCLUSION}

Conclusively, the study assessed risk factors for mycotoxin contamination in cereals in Iringa municipality. In which majority of respondents 171 individuals equivalent to $87.2 \%$ did not have knowledge on mycotoxin contamination in cereals, while only 25 individuals equivalent to $12.8 \%$ had knowledge on mycotoxin contamination in cereals. While the storage conditions and facilities used, showed that majority of individuals $111(77.6 \%$ ) piled up bags of cereals on bare floors (no pallets) and $87(60.8 \%$ ) leaned them directly against the walls with majority of them $96(67.1 \%)$ placed under roofs with no ceiling.

Food processing method that majority 109(55.6\%) performed was drying of cereals before further processing or storage, despite majority dry their cereals only $80(40.8 \%)$ of respondents understand that drying reduces risk of fungi contamination in cereals while the large number of respondents $116(59.2 \%)$ do not understand the significance of drying in relation to reduction in risk of fungi contamination. 


\section{RECOMMENDATIONS}

1. Intervention should be taken to raise awareness regarding mycotoxin contamination in cereals, as majority $87.2 \%$ do not have knowledge concerning mycotoxin contamination.

2. Use of pallets to place cereal bags away from the ground, as majority $77.6 \%$ do not have pallets. Cereal packaging materials, such as woven sack can be made hermetic by tightly folding and stitching the sack to prevent attraction of fungi and other insects, should be placed under roofs with ceiling to be able to control temperature of the storage room and prevent entry of water during rain.

3. Facilities should be cleaned before storage or usage, as majority $55.2 \%$ do not clean their milling machines before processing, leads to feedstuffs building up on the inside walls of machines and facilities, but also packages scattered all over the ground, potentially encouraging fungal growth and cross-contamination as majority $53.1 \%$ do not clean their storages.

\section{ABBREVIATIONS}

AFB1 - Aflatoxin B1

AFB2 - Aflatoxin B2

AFG1 - Aflatoxin G1

AFG2 - Aflatoxin G1

BGYF - Bright Greenish-Yellow Fluorescence

CAC - Codex Alimentarius Commission

CIT - Citrinin

DAS - Diacetoxyscir- penol

DON - Deoxynivalenol

Et. al - And Others

FAO - Food and Agriculture Organisation

FB1 - Fumonisins B1

FB2 - Fumonisins B2

GAP - Good Agriculture Practices

GMP - Good Manufacturing Practices

HBV - Hepatitis B virus

IARC - International Agency for Research on Cancer

JECFA - Joint FAO/WHO Expert Committee on Food Additives

NIV - Nivalenol

OTA - Ochratoxin A 
TFDA - Tanzania Food, Drugs and cosmetics Authority

USDA - United States Department of Agriculture

WFP - World Food Programme

WHO - World Health Organization

ZEN - Zearalenone

\section{REFERENCES.}

1. Ashton Acton (2011). Mycotoxins: Advances in Research \& Application.

2. Babbie, Earl R., (2010). The Practice of Social Research $\left(12^{\text {th }}\right.$ ed.). Wadsworth: Cengage Learning.

3. Baheeja, (2017). Major Groups of Mycotoxins.

4. Bakirdere et al., (2012). Determination of trace aflatoxin M1 levels in milk and milk products consumed in Turkey by Enzyme-linked Immuno-Sorbent Assay.

5. Benett JW., Klich M., (2003). Myotoxins.

6. Clara Bernice Darko, 2016. Effects of Storage Conditions on Aspergillus Growth and Aflatoxin Production in Peanuts: A study in Ghana.

7. Claudia Probst, Henry Njapau, et al., 2004. Outbreak of Acute Aflatoxicosis in Kenya: Identifiation of Casual Agent

8. Codex Alimentarius Commission (2003). Code of Practice for the Prevention and Reduction of Mycotoxin Contamination in Cereals.

9. Coreal, et al. (2015). European Guide to Good Hygiene Practices for the collection, storage, trading and transport of cereals, oilseeds, protein crops, other plant products and products derived there of.

10. Doughari JH., 2015. The occurrence, Properties and Significance of Citrinin Mycotoxin. J Plant Pathol Microbiol Felicia Wu, et al., (2014). Public Health Impacts of Food borne Myotoxin

11. Felix D'Mello, J.P., (2003). Food Safety: Contaminants and Toxins. Center for agriculture and Bioscience International

12. Gao F., Jiang LP., et. al., (2013). Genotoxic Effects induced by Zearalenone in Human Embryonic Kidney cell line.

13. Geary PA, Chen G, Kimanya ME, et al. (5 more authors) (2016). Determination of multi mycotoxin occurrence in maize based porridges from selected regions of Tanzania by liquid chromatography tandem mass spectrometry (LC-MS/MS), a longitudinal study. Food Control, 68. pp. 337-343. 
14. Ifeoluwa Adekoya, Patrick Njobeh, Adewale Obadina, Cynthia Chilaka, Sheila Okoth, Marthe De Boevre \& Sarah De Saeger, 2017. Awareness and Prevalence of Mycotoxin Contamination in Selected Nigerian Fermented Foods.

15. James Kandoya. (2016, August 02). Health ministry set to extend tests to curb Aflatoxicosis diseases. The Guardian

16. Kate Ann Levin (2006). Study Design III: Cross Sectional Studies 'Evidence- based Dentistry, vol. 7, no.1, pp. 24-25.

17. Lubinda Mbundi, Rosa Busquets et al., (2014). Advances in Molecular Toxicology (vol.11).

18. Ministry of Health, Community Development, Gender, Elderly and Children (MoHCDGEC) [Tanzania Mainland], Ministry of Health (MoH) [Zanzibar], Tanzania Food and Nutrition Centre (TFNC), National Bureau of Statistics (NBS), Office of the Chief Government Statistician (OCGS) [Zanzibar] and UNICEF. 2018. Tanzania National Nutrition Survey using SMART Methodology (TNNS) 2018. Dar es Salaam, Tanzania: MoHCDGEC, MoH, TFNC, NBS, OCGS, and UNICEF.

19. Petr Karlovsky, Michele Suman, Franz Berthiller, et. al, (2016). Impact of food processing and detoxification treatments on mycotoxin contamination.

20. Rajasekar, et. al. (2006). Research Methodology

21. Selestin Ngoma, Bendantukuka Tiisekwa, Dismas mwaseba, Martin Kimanya, 2017. Awareness of aflatoxin Health Risks Among parents with Children aged between 623months in central Tanzania. International Journal of Nutrition and Food Sciences.

22. Tanzania Food, Drugs and Cosmetics Authority (2012).Aflatoxin Contamination and Potential Solutions for Its Control in Tanzania.

23. United Nations World Food Programme (2012). Training Manual for Improving Grain Postharvest Handling and Storage.

24. United States Department of Agriculture (2015). Mycotoxin Handbook. Grain Inspection, Packers and Stockyards Administration

25. Vladimir ostry, et al., (2016). Mycotoxins as human Carcinogens.International Agency for Research on Cancer

26. World Health Organisation (1999). Toxic Effects of Mycotoxins in Humans.

27. World Health Organization (2017). Weekly Bulletin on Outbreaks and Other Emergencies.

28. Yogendrarajah, Van Poucke, De Meulenaer, \& De Saeger, (2013). Development and validation of QuEChERS based liquid chromatography tandem mass spectrometry method for the determination of multiple mycotoxins in spices 
29. Zengran Liu, Guangyi Zhang, Yi Zhang, Qiuxiao Jin, Jing Zhao, et al.. Factors controlling mycotoxin contamination in maize and food in the Hebei province, China. Agronomy for Sustainable Development, Springer Verlag/EDP Sciences/INRA, 2016, $36(2)$, pp.39.

\section{DECLARATION}

\section{Ethics Approval and Consent Participation}

The study was approved by Ruaha University and Iringa Municipality, Tanzania. All respondents were informed about the nature of the study, refusal to answer to any question that they deemed sensitive, the data collection procedures and confidentiality. The Data collection methods used in this study were in accordance to ethical standards and human rights. Both verbal and written informed consent was obtained before administering questionnaires and checklist. To ensure privacy and anonymity names were not included on Questionnaires, while names of facilities where checklist was used confidentiality was observed.

\section{Consent for Publication}

Not applicable.

\section{Availability of Data and Materials}

The dataset is with the corresponding author, available upon request.

\section{Competing Interest}

Authors have no competing Interest.

\section{Funding}

Not Applicable.

\section{Authors' Contribution}

RAR wrote the research proposal and analysed the data. P M C the manuscript and $\mathrm{R} \mathrm{M}$ did the technical check of the work. All authors approved the final draft of the Manuscript.

\section{Acknowledgement}

We would like to express our special thanks to the Department of Environmental Health Sciences in RUCU for their valuable contributions, assistance and useful comments. 
Figures

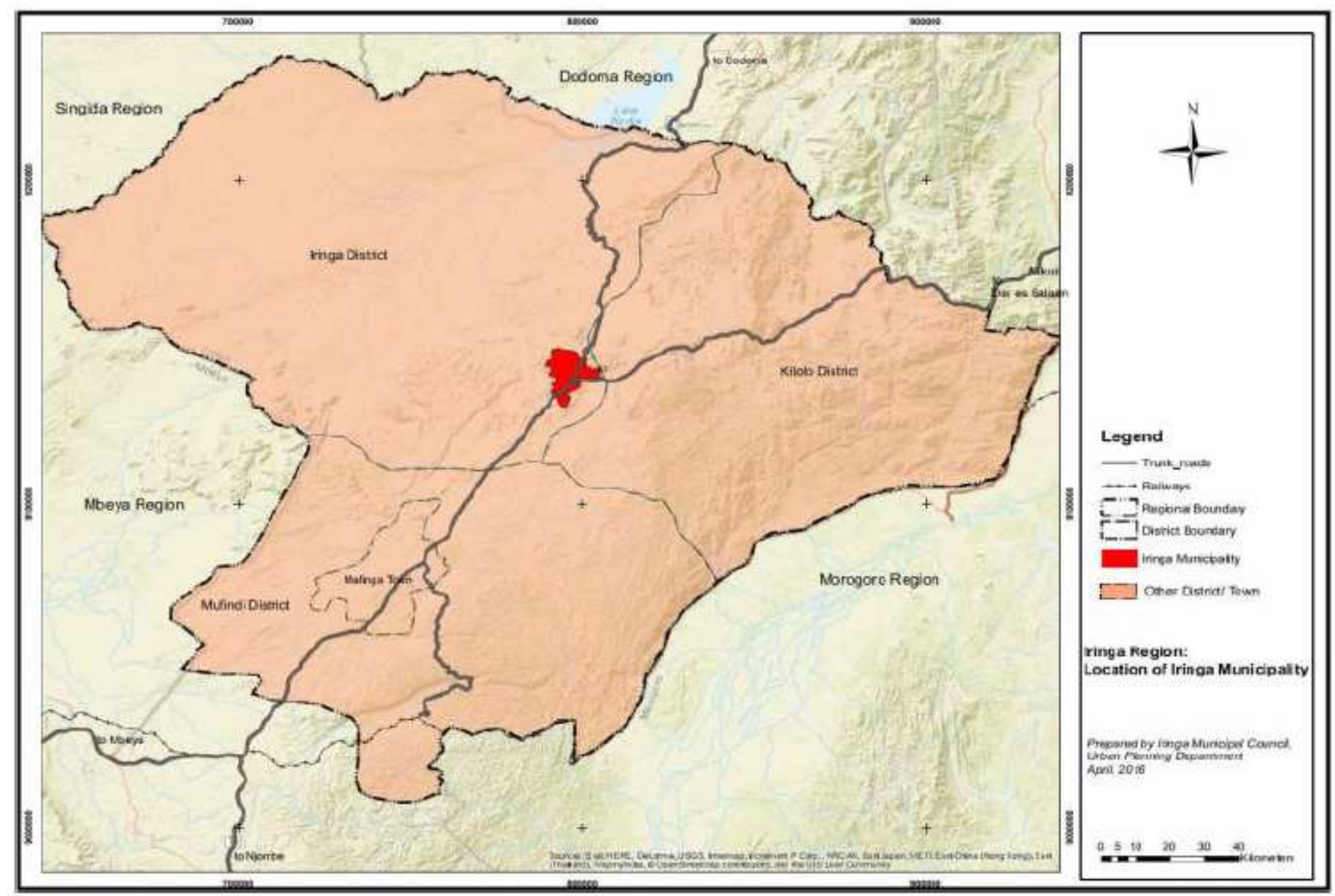

Figure 1

Iringa Municipality map (Source Google Map). Note: The designations employed and the presentation of the material on this map do not imply the expression of any opinion whatsoever on the part of Research Square concerning the legal status of any country, territory, city or area or of its authorities, or concerning the delimitation of its frontiers or boundaries. This map has been provided by the authors. 


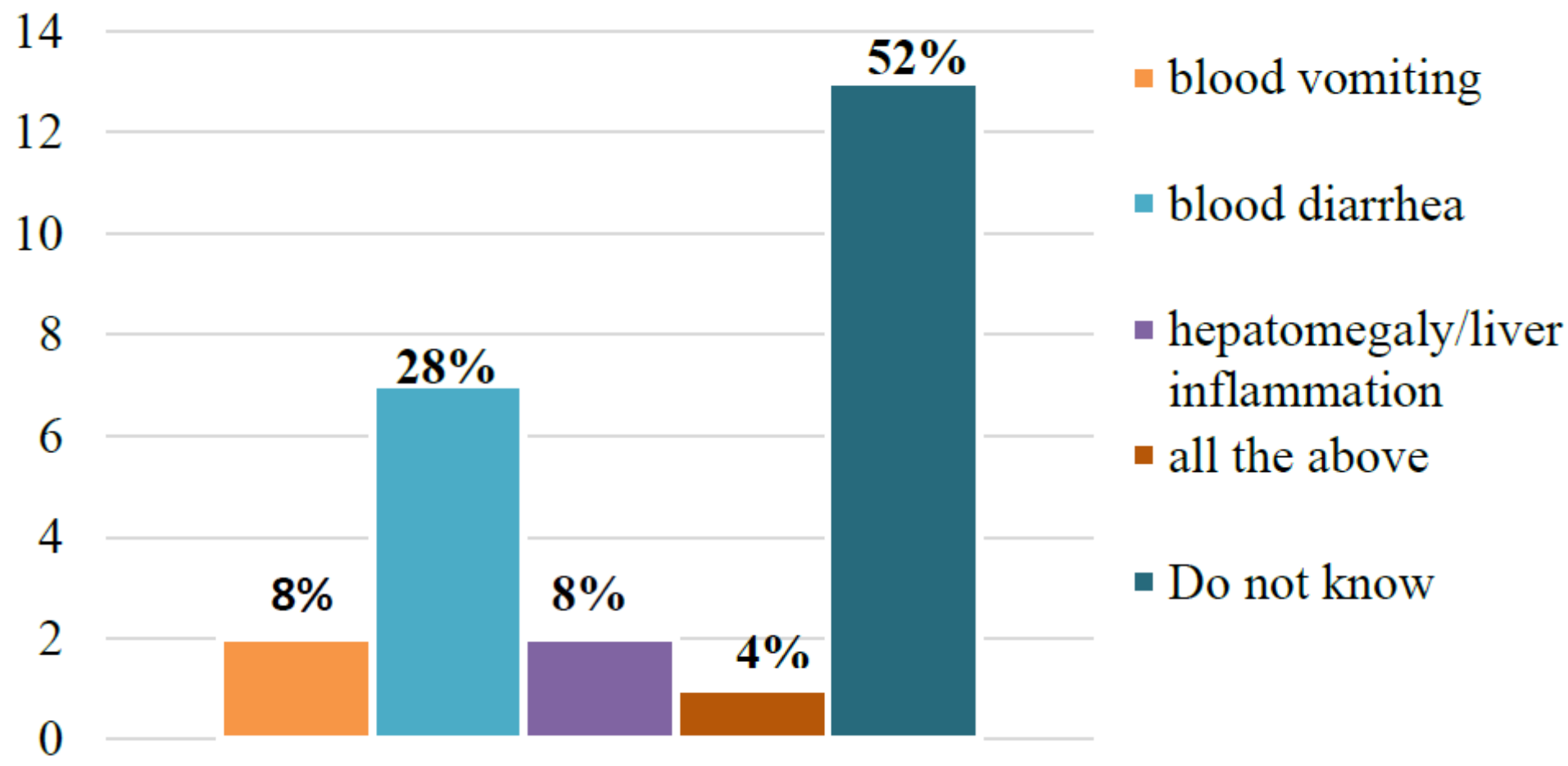

Figure 2

Knowledge on acute health effects on consumption of mycotoxin contaminated cereal 16

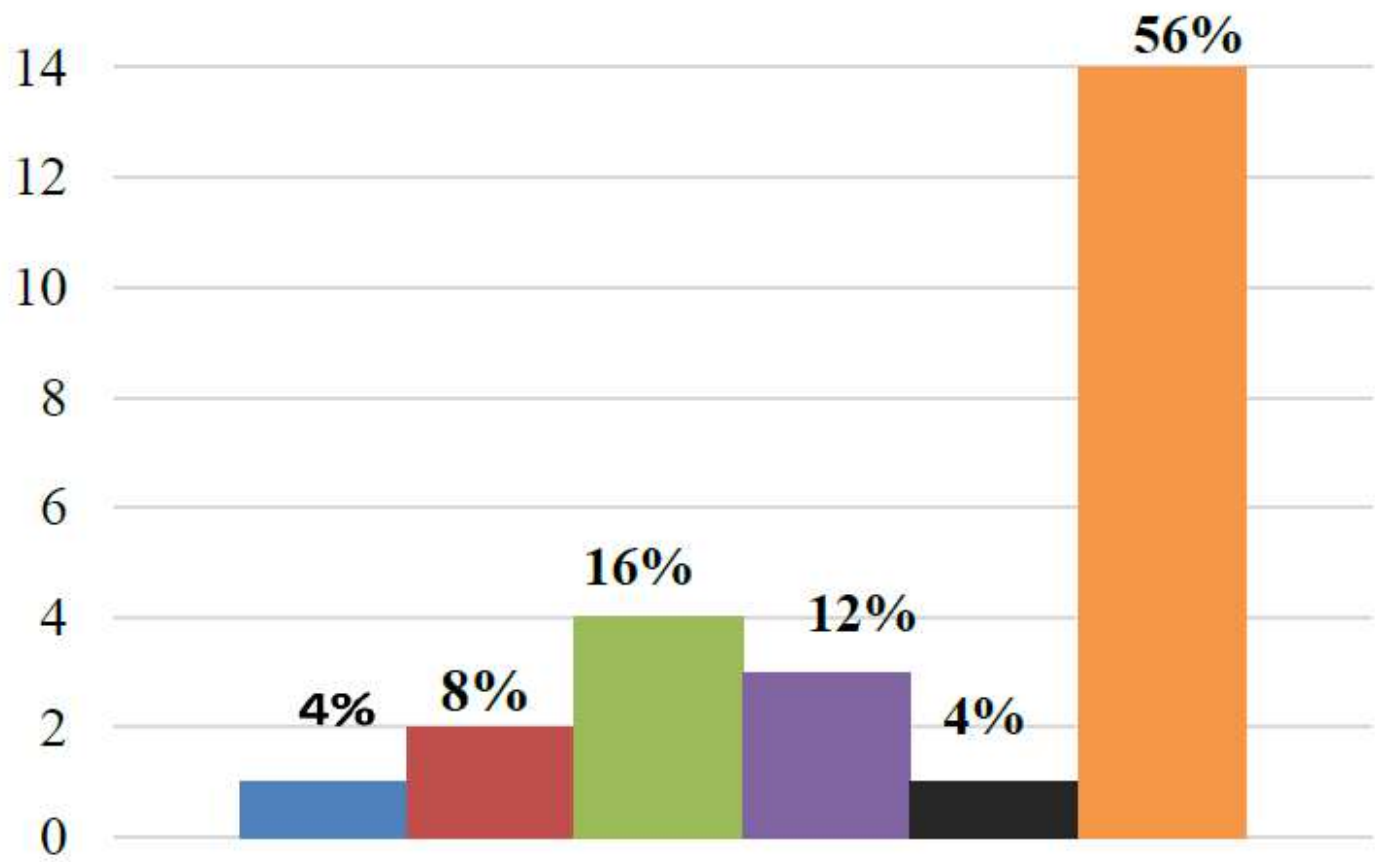

liver cancer immune system suppression stunted growth

liver damage

all the above

Do not know

\section{Figure 3}

Knowledge on chronic health effects on consumption of mycotoxin contaminated cereal 